\title{
OCULAR BIOMETRIC STUDY DURING ACCOMMODATION
}

\section{SHRIKANT DESHPANDE}

\author{
*Corresponding Author: Email- kant123@rediffmail.com
}

Received: April 26, 2012; Accepted: May 10, 2012

\begin{abstract}
We performed this study to measure the ocular changes during accommodation and see whether refractive error has any influence in effect of changes during accommodation. This study was carried out in the Department of Ophthalmology, Pt. B. D. Sharma PGIMS, Rohtak. Seventy five subjects were divided in three groups according to refractive status. Group A consisted of 25 emmetropes. Group B consisted of 25 myopes with myopia $<5 \mathrm{D}$ while Group $\mathrm{C}$ consisted of 25 hypermetropes with hypermetropia $<5 \mathrm{D}$. The subject was asked to focus on 6/6 line of Snellen's chart kept at a distance of 6 meters with full refractive correction with the left eye and A-scan was performed on the right eye. Three readings of anterior chamber depth, lens thickness and axial length were taken and the mean values of these reading were calculated. Similar procedure was repeated after accommodation. Accommodation was achieved by asking the subject to focus on N/6 line of near vision chart held at a distance of $33 \mathrm{~cm}$ with left eye with full refractive correction on the left eye. Then, the subjects were asked to focus N/6 line of near vision chart held at $12.5 \mathrm{~cm}$ to increase the amplitude of accommodation and similar procedure was repeated. The mean increase in axial length was $0.051,0.004$, and $0.005 \mathrm{~mm}$ in Groups $A, B$ and $C$ respectively when focus of the left eye was shifted from $6 \mathrm{~m}$ to $33 \mathrm{~cm}$. On further increasing the accommodation by shifting the focus of the left eye to $12.5 \mathrm{~cm}$, the axial length increased by $0.08,0.07$, and $0.007 \mathrm{~mm}$ in Groups $\mathrm{A}, \mathrm{B}$, and $\mathrm{C}$ respectively. Increase in lens thickness and decrease in anterior chamber depth were also observed with accommodation in all three groups. There was no significant difference in between three groups in these changes. Conclusions: Subtle but statistically significant increase in axial length was observed with accommodation in this study. There was increase in lens thickness and decrease in anterior chamber depth with accommodation. There was no variation with refractive error in these changes.
\end{abstract}

Keywords- axial length, accommodation, A-scan

Citation: Shrikant Deshpande (2012) Ocular biometric study during accommodation. International Journal of Medical and Clinical Research, ISSN:0976-5530 \& E-ISSN:0976-5549, Volume 3, Issue 4, pp.-150-153.

Copyright: Copyright@2012 Shrikant Deshpande. This is an open-access article distributed under the terms of the Creative Commons Attribution License, which permits unrestricted use, distribution, and reproduction in any medium, provided the original author and source are credited.

\section{Introduction:}

Human eyes have been provided with a unique mechanism by which we can focus the diverging rays coming from a near object on the retina to see clearly. This mechanism is called as accommodation. This is achieved by changing thickness of lens by action of ciliary muscles and zonules upon it. Various methods like slit-lamp photography, optical pachymetry, A-scan ultrasonography, and partial coherence inferometry have been used to observe the changes in ocular structures during accommodation.
Out of these, A-scan ultrasonography is widely available and provides reliable information on the position of major refractive surfaces of the eye.

Studies carried out on this subject have yielded different and inconclusive results. Some studies reported increase in axial length during accommodation whereas others have reported no change in axial length during accommodation.

Mcbrien et al reported amplitude of accommodation differs according to the refractive error. They have reported higher ampli- 
tude of accommodation in myopes as compared with emmetropes [1]. Hence, the ocular changes during accommodation may differ according to refractive status of the eye.

Mallen et al reported greater change in axial length in myopes as compared with emmetropes[2]. No study has been carried out to compare the difference of changes during accommodation in myopes and hypermetropes. This study was carried out to measure the ocular changes during accommodation and see whether refractive error has any influence in effect of changes during accommodation.

\section{Material and methods}

This study was carried out in the Department of Ophthalmology, Pt. B. D. Sharma PGIMS, Rohtak. Seventy five subjects were included in this study after written and informed consent. The subjects were divided in three groups according to refractive status. Group A consisted of 25 emmetropes. Group B consisted of 25 myopes with myopia $<5 \mathrm{D}$ while Group $\mathrm{C}$ consisted of 25 hypermetropes with hypermetropia $<5 D$.

\section{Exclusion criteria}

Patients having following were excluded from the study:

1. Age less than 18 year or more than 30 years

2. Convergence insufficiency

3. Amblyopia

4. Strabismus

5. Other diseases affecting visual acuity e.g. any media opacity, corneal surface irregularities, uveitis, macular diseases

6. Best corrected visual acuity $<6 / 6$

7. Myopia $>5 \mathrm{D}$; hypermetropia $>5 \mathrm{D}$

8. Intraocular pressure $>24 \mathrm{~mm} \mathrm{Hg}$

Preliminary examination included keratometry, measurement of intraocular pressure, slit lamp examination and fundus examination.

The refractive error was determined by retinoscopy carried out one and half hour after instillation of one drop of $1 \%$ cyclopentolate for three times at the interval of ten minutes.

Subjects were made to sit upright. Fisher et al showed that monocularly and bimocularly induced accommodative effect are similar in magnitude[3]. Hence, the left eye was used for fixation and right eye was used for biometric studies.

Biomedix Echorule A-scan ultrasonography machine was used in this study. It has a frequency of $10 \mathrm{MHz}$. Contact type of probe was in this study. Velocities of sound through anterior chamber, lens and vitreous chamber fed in the machine were 1532, 1641 and $1532 \mathrm{~m} / \mathrm{s}$ respectively. Biometry was performed in phakic mode with gain setting of $70 \%$.

Right eye was anaesthetized using topical $4 \%$ lignocaine eye drops. The subject was asked to focus on 6/6 line of Snellen's chart kept at a distance of 6 meters with full refractive correction on the left eye. Lids of the right eye were gently separated with fingers without applying any pressure on the globe. A-scan probe tip was gently put on the center of cornea with its direction along the visual axis perpendicular to cornea. Before proceeding further it was ensured that the subject has sharp image of $6 / 6$ line of Snellen's chart with left eye.

The echo-spikes were observed for height of echoes indicating amplitude and sharpness. Readings were taken by freezing the Ascan by pressing the foot-pedal. Readings were taken only when following condition were fulfilled which indicated that the probe was aligned along the visual axis:

1. Tall and sharp echoes from cornea, anterior lens surface, posterior lens surface and vitreo-retinal surface.

2. The retinal echoes should be steeply rising without any steps, humps or jags.

3. Presence of scleral echoes

Three readings of anterior chamber depth, lens thickness and axial length were taken and the mean values of these reading were calculated.

Similar procedure was repeated after accommodation. Accommodation was achieved by asking the subject to focus on N/6 line of near vision chart [Roman test type] held at a distance of $33 \mathrm{~cm}$ with left eye with full refractive correction on the left eye. It was ensured that the subjects had clear and sharp image of letters on $\mathrm{N} / 6$ line. Biometry was performed on the right eye simultaneously and readings of anterior chamber depth, lens thickness and axial length were taken.

Then, the subjects were asked to focus N/6 line of near vision chart held at $12.5 \mathrm{~cm}$ to increase the amplitude of accommodation and similar procedure was repeated.

The accommodation was relaxed by adding $+3 D$ to the refractive correction on the left eye. The subjects were then asked to focus at N/6 line of near vision chart held at $33 \mathrm{~cm}$ with left eye. Biometric procedures were done on the right eye.

Statistical analysis of the above readings was carried out by using paired and unpaired 't' tests.

\section{Observations and Results}

There was no significant difference in treatment groups with respect to age and sex distribution. Group $B$ consisted of myopes with mean refractive error of $-1.93 \pm 1.39$ in right eye and $-2.03 \pm$ 1.09 in left eye. The mean refractive error of group $C$ was $+1.9 \pm$ 1.28 in right eye and $+1.69 \pm 1.21$ in left eye. Group A comprised of emmetropes.

An increase in axial length with accommodation was noted in all three groups. The mean increase in axial length of Group A was $0.051 \mathrm{~mm}$ when focus of the left eye was shifted from $6 \mathrm{~m}$ to 33 $\mathrm{cm}$. On further increasing the accommodation by shifting the focus of the left eye to $12.5 \mathrm{~cm}$, the axial length increased by $0.088 \mathrm{~mm}$. Similar results were obtained in Groups B and C. The increase in axial length during accommodation was found be statistically significant in all three groups with paired ' $t$ ' test.

The anterior chamber depth decreased with accommodation in all three groups. The mean decrease in axial length of Group A was $0.09 \mathrm{~mm}$ when focus of the left eye was shifted from $6 \mathrm{~m}$ to $33 \mathrm{~cm}$. On further increasing the accommodation by shifting the focus of the left eye to $12.5 \mathrm{~cm}$, the anterior chamber depth decreased by $0.12 \mathrm{~mm}$. Similar results were obtained in Groups B and C. The decrease in anterior chamber depth during accommodation was found be statistically significant in all three groups with paired ' $t$ ' test.

An increase in lens thickness with accommodation was noted in all three groups. The mean increase in lens thickness of Group A was $0.09 \mathrm{~mm}$ when focus of the left eye was shifted from $6 \mathrm{~m}$ to $33 \mathrm{~cm}$. On further increasing the accommodation by shifting the 
focus of the left eye to $12.5 \mathrm{~cm}$, the lens thickness increased by $0.15 \mathrm{~mm}$. Similar results were obtained in Groups B and C. The increase in lens thickness during accommodation was found be statistically significant in all three groups with paired 't' test.

The mean change in axial length on shifting focus of left eye from $6 \mathrm{~m}$ to $33 \mathrm{~cm}$ was compared in between groups $A, B$ and $C$. With the help of unpaired 't' test, ' $p$ ' value of $>0.1$ was obtained when group $A$ with group $C$ and group $B$ with group $C$. Thus, the difference of change in axial length on accommodation in between groups $A, B$ and $C$ was statistically insignificant. Similarly, change in anterior chamber depth and lens thickness was compared in between groups $A, B$ and $C$ with the help of unpaired ' $t$ ' test and $p$ value of $>0.1$ was obtained in all comparisons.

\section{Discussion}

Decrease in anterior chamber depth with accommodation was noted in this study in 66 out of 75 subjects. Read et al[4], Storey et al[5], Shum et al[6] and Garner et al[7] have all reported decrease in anterior chamber depth with accommodation in their studies done with A-scan ultrasonography. Studies by methods other than ultrasonography have also yielded similar result. Calmettes et al found reduction in anterior chamber depth ranging between 0.1 to $0.5 \mathrm{~mm}$ with a mean of $0.23 \mathrm{~mm}$ with accommodation in their study using optical pachymetry[8]. Thus, the decrease in anterior chamber depth during accommodation as observed in our study is consistent with other studies carried put on this subject so far. The decrease in anterior chamber depth during accommodation may due to forward movement of the anterior surface of the lens and an increase in anterio-posterior diameter of the lens during accommodation as noted by reported by Kalzuny[9] and Brown[10]. There was significant increase in lens thickness with accommodation in 60 out of 75 subjects in this study. Read et al[4], Storey et al[5], Shum et al[6] and Garner et al [7] have reported increase in lens thickness with accommodation in their studies done with Ascan ultrasonography. Studies using slit-lamp photography[11] and partial coherence interferometry[12] have also reported increase in lens thickness with accommodation. The increase in lens thickness with accommodation can be easily explained by Helmholtz's theory of relaxation. According to this theory, contraction of ciliary muscle causes the ciliary ring to shorten and move towards the equator of the lens. As a result, the zonules are relaxed relieving the tension on the lens capsule. Fincham suggested that the lens attains more spherical shape during accommodation due to the elasticity of the lens capsule which causes increase in its thickness during accommodation[13].

In the present study, axial length increased with accommodation in 54 out of 75 subjects; while it deceased in 20 subjects and remained unchanged in 1 subject. The mean increase in the axial length on shifting the focus of the left eye from $6 \mathrm{~m}$ to $33 \mathrm{~cm}$ was $0.051,0.052$ and $0.047 \mathrm{~mm}$ in group $A, B$ and $C$ respectively. On shifting the focus to $12.5 \mathrm{~cm}$, the axial length increased by 0.088 , 0.077 and $0.077 \mathrm{~mm}$ in group $\mathrm{A}, \mathrm{B}$ and $\mathrm{C}$ respectively. Although the changes in axial length with accommodation were subtle; they were statistically significant as found out by paired 't' tests.

Read et al[4] and woodman et al[14] reported an increase in axial length during accommodation. Story et al reported mean increase of $0.08 \mathrm{~mm}$ with $2 \mathrm{D}$ of accommodation stimulus in their study carried on 14 subjects carried out with increased with accommo- dation in most of the subjects. The mean increase in axial length on accommodation was $0.05 \mathrm{~mm}$ when the focus shifted from $6 \mathrm{~m}$ $33 \mathrm{~cm}[5]$. Drexler et al studies accommodative changes with partial coherence interferometry and found that axial length increased with accommodation in most of their subjects[12].

The increase in axial length during accommodation can be explained by Coleman's unified model of accommodation in which he attributed an active role to vitreous chamber in addition to the relaxation hypothesis of Helmholtz. He hypothesized that a pressure gradient between the compressed vitreous and the anterior chamber may occur during accommodation, which may exert stress on the sclera[15].

Shum et al proposal that accommodation might induce an increase in vitreous pressure, which may cause the vitreous chamber to expand and the sclera; which is an elastic to stretch. They further proposed that as the posterior pole is the most extensible pert of the sclera, accommodation causes it to be stretched thereby increasing the axial length. During accommodation, the change in the lens may not be sufficient to focus the image exactly on the retina. A small backward movement of the posterior pole may strengthen the accommodative effect. The near object may then from a clear image on the retina[6].

In support to Shum's hypothesis, Tokoro et al found that the sclera distended in a longitudinal direction at the equator and in both latitudinal and longitudinal direction at the posterior pole with increasing pole with increasing vitreous pressure[16].

Excess near work is linked with myopia in various population based studies[17]. Continuous use of accommodation during near work may lead to permanent increase in axial length and may lead to myopia.

This study did not find any significant relationship between the accommodation changes in interior chamber depth, lens thickness and axial length with refractive error of the eye.

Limitations of this study include small sample size and use of contact probe for ultrasonography. Studies using immersion method or partial coherence inferometry on large number of subjects may shed further light on this subject.

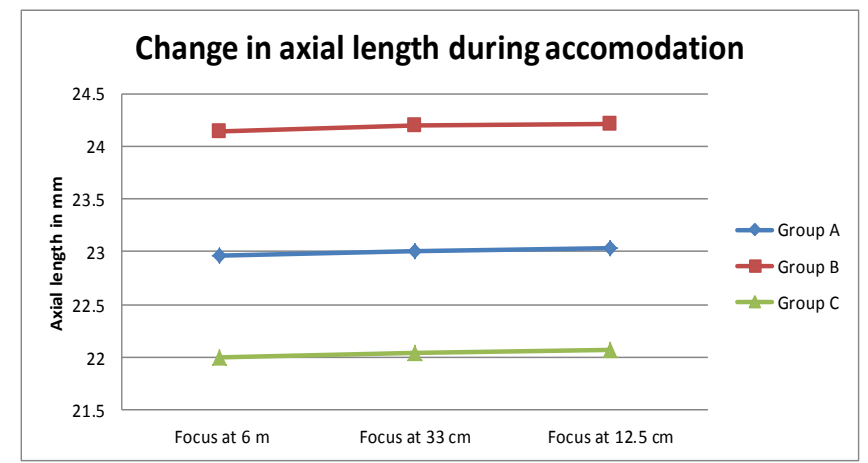

Graph- Changes in axial length during accommodation

Table 1- Changes in axial length during accommodation

\begin{tabular}{|lllll|}
\hline Sr. No. Axial length [mm] & Group A & Group B & Group C \\
\hline 1 & Focus at $6 \mathrm{~m}$ & $22.96+0.62$ & $24.14+0.79$ & $22.00+0.94$ \\
2 & Focus at $33 \mathrm{~cm}$ & $23.01+0.63^{*}$ & $24.19+0.80^{*}$ & $22.04+0.93^{*}$ \\
3 & Focus at $12.5 \mathrm{~cm}$ & $23.04+0.64^{*}$ & $24.21+0.81^{*}$ & $22.07+0.91^{*}$ \\
4 & Focus at 33cm With +3 D & $22.96+0.62$ & $24.14+0.79$ & $22.00+0.94$ \\
\hline
\end{tabular}

*statistically significant $(p<0.05)$ 
Table 2- Changes in anterior chamber depth during accommoda-

tion

\begin{tabular}{|c|c|c|c|c|}
\hline Sr. No & . Anterior chamber depth [mm] & Group A & Group B & Group C \\
\hline 1. & Focus at $6 \mathrm{~m}$ & $3.32+0.30$ & $3.45+0.26$ & $3.00+0.24$ \\
\hline 2. & Focus at $33 \mathrm{~cm}$ & $3.23+0.29^{*}$ & $3.35+0.27^{*}$ & $2.90+0.22^{*}$ \\
\hline 3. & Focus at $12.5 \mathrm{~cm}$ & $3.20+0.31^{*}$ & $3.33+0.29^{*}$ & $2.87+0.21^{*}$ \\
\hline 4. & Focus at $33 \mathrm{~cm}$ With $+3 \mathrm{D}$ & $3.31+0.30$ & $3.44+0.27$ & $2.99+0.23$ \\
\hline
\end{tabular}

*statistically significant $(p<0.05)$

Table 3- changes in lens thickness during accommodation

\begin{tabular}{|c|c|c|c|}
\hline Sr. No. Lens thickness & Group A & Group B & Group C \\
\hline 1. Focus at $6 \mathrm{~m}$ & $3.88+0.22$ & $3.92+0.23$ & $4.00+0.20$ \\
\hline Focus at $33 \mathrm{~cm}$ & $3.98+0.24^{*}$ & $4.00+0.22^{*}$ & $4.10+0.19^{*}$ \\
\hline Focus at $12.5 \mathrm{~cm}$ & $4.03+0.25^{*}$ & $4.04+0.22 *$ & $4.13+0.20^{*}$ \\
\hline Focus at $33 \mathrm{~cm}$ With $+3 \mathrm{D}$ & $3.89+0.23$ & $3.92+0.23$ & $4.01+0.19$ \\
\hline
\end{tabular}

*statistically significant $(p<0.05)$

\section{Conclusions}

This study reported a small but consistent increase in axial length during accommodation with A-scan ultrasonography. This may be responsible for myopia due to excess near work. This study also showed decrease in anterior chamber depth and increase in lens thickness with increasing levels of accommodation. This study did not find significant correlation in refractive status and ocular changes during accommodation.

\section{References}

[1] Mcbrien N., Millodot M. (1986) Invest Ophthalmol Vis Sci 27, 1187-9.

[2] Mallen E.A., Kashyap P., Hampson K.M. (2006) Invest Ophthalmol Vis Sci, 47(3), 1251-4.

[3] Fisher R.F. (1983) Br. J. Ophthalmol, 67, 206.

[4] Read S.A., Collins M.J., Iskander D.R. (2008) Invest Ophthalmol Vis. Sci. 49(7), 2911-8.

[5] Storey J.K., Rabie F.P. (1985) Ophthalmic Physiol Opt. 5, 145-8.

[6] Shum P.J.T., Ko L.S., Ng C.L., Lin S.L. (1993) Am J Ophthalmol, 115, 76-81.

[7] Garner L.F., Yap M.K. (1997) Ophthalmic Physiol Opt, 17, $12-$ 7.

[8] Calmettes, Deodati, Huron, Bechac (1966) Arch Ophthalmol $18,513-42$

[9] Kaluzny B.J. (2007) Eur. J. Ophthalmol 17(4), 515-20.

[10]Brown N. (1973) Exp Eye Res, 15, 441-59.

[11]Patnaik B. (1967) Invest Ophthalmol Vis Sci, 6, 601-11

[12]Drexler W., Baumgartner A., Findl O., Hitzenberger C.K., Fercher A.F. (1997) Vision Res, 37, 2789-800.

[13]Fincham E.F. (1951) Br. J. Ophthalmol, 35, 381-93.

[14]Woodman E.C., Read S.A., Collins M.J., Hegarty K.J. (2011) Br. J. Ophthalmol 95(5), 652-6.

[15]Coleman D.J. (1970) Am. J. Ophthamol, 69,1063-79.

[16]Tokoro T. (1998) Nihon Ganka Gakkai Zasshi 102(12), $796-$ 812.

[17]Ip J.M., Saw S.M., Rose K.A., Morgan I.G., Kifley A., Wang J.J., Mitchell P. (2008) Invest Ophthalmol Vis. Sci. 49(7), 2903-10. 